\title{
Optimized Selection of Solar Cell for A Nano-Satellite According to A Mathematical Model of Subsystem's Required Power
}

\author{
Farid Salehinia ${ }^{1}$, NimaNaghieh $^{2}$, Seyed Nasirodin Mirmohammadi ${ }^{3}$ \\ ${ }^{I}$ M.Sc in Power Engineering, Isfahan, Iran, fsalehinia1989@gmail.com \\ ${ }^{2}$ M.Sc in Electrical Engineering, Shahrood University of Technology, Iran, pgmdown@yahoo.com \\ ${ }^{3}$ M.Sc in IT Engineering, Vancouver, Canada, snasir.mir@gmail.com
}

\begin{abstract}
The purpose of this paper is to have an optimized selection of solar cells for a telecommunication Nano-satellite by the maximum and the minimum longevity of 2 and 1 years, respectively. Also by considering the orbital height of $500 \mathrm{~km}$, average power of 10.4 watt, maximum power of 35 watt, eclipse period of 35.75 minutes, and through the Direct Energy Transmission (DET) approach. At first, the subsystem's required information of different telecommunication Nano-satellite will be collected, then the designing of satellite power system will be done based on a mathematical model. Then according to the simulation results in MATLAB/Simulink an optimized solar cell will be selected.
\end{abstract}

Keywords:Solar Cell Optimization, Power Supply Subsystem, Telecommunication Nano-Satellite, Direct Energy Transmission Method.

\section{Introduction}

Most of the Nano-Satellites in terms of dimension are between 10 and $50 \mathrm{~cm}$, in terms of weight are in a 1 to $10 \mathrm{~kg}$ mass range, and in terms of commission longevity are between 3 days and 1 year. The under study Nano-Satellite in this paper is preparing and sending profitable and useful images. In order to have a complete coverage of earth we should have 350 of these Nano-Satellites in $500 \mathrm{~km}$ height from the earth surface.

\section{The Electric Power Subsystem Model}

The beginning point of satellites design is to consider a sampled Electric Power Subsystem (EPS) model based on fixed charges. The EPS model is based on orbital energy balance. It means that the amount of energy taken from battery in eclipse time should be equal to the amount of energy in non-eclipse time. This concept can be expressed as bellow:

$$
\text { Equation (1): } P_{b d} \times T_{c} \leq P_{b c} \times T_{d}
$$

The equation (1) shows that the multiplication of charging time in charging battery power should be greater or equal to the multiplication of discharging time in discharging battery power. Due to the fixed state of battery -charging or discharging- therefore the sum of $T_{d}$ and $T_{c}$ equals to orbital period $\left(T=T_{d}+T_{c}\right)$. In an ordinary working day, the total amount of required energy for charges and battery charging prepares by solar arrays, and in eclipse time the required energy supplies through the battery.

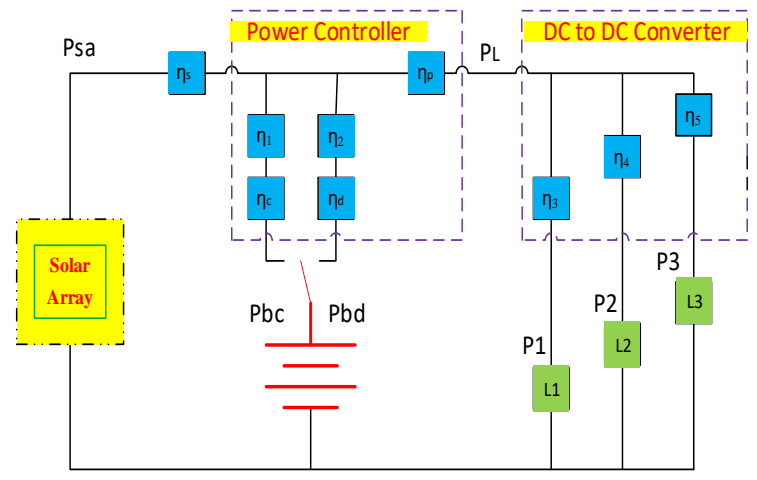

Figure 1: The Equivalent Orbit for Satellite Electrical Power Sub-System

The charges required power supplies by solar arrays and the remained charges of the required power is taken from battery. Hence, the power gained from the battery is in fact the difference between the charges required power and the produced power by solar cells. The battery power in discharging time is as: 


$$
\text { Equation (2): } P_{b d}=\frac{P_{L} / \eta_{p}-P_{s a} \eta_{s}}{\eta_{d} \eta_{2}}
$$

The equation (2) shows that the battery is dischargeable in each time, whether in eclipse time or not. The power in the battery charging time is the difference between powers of solar arrays and charges required power. If charges use the total power from solar cells, the batteries do not charge anymore. The sending power to the batteries in charging time is:

$$
\text { Equation (3): } P_{b c}=\left(P_{s a} \eta_{s}-\frac{P_{L}}{\eta_{p}}\right) \eta_{1} \eta_{c}
$$

By substitution of equations (2) and (3) in equation (1):

$$
\text { Equation (4): }\left[\frac{\left(\frac{P_{L}}{\eta_{p}}\right)-P_{s a} \eta_{s}}{\eta_{d} \eta_{2}}\right] T_{d} \leq\left[\left(P_{s a} \eta_{s}-\frac{P_{L}}{\eta_{p}}\right)-\eta_{1} \eta_{c}\right] T_{c}
$$

By solving of equations (4) and acquiring $\mathrm{P}_{\mathrm{sa}}$ :

$$
\begin{gathered}
P_{s a}=\frac{P_{L} T_{d}}{\eta_{p}\left(\eta_{s} \eta_{1} \eta_{c} \eta_{d} \eta_{2} T_{c}+\eta_{s} T_{d}\right)}+\frac{P_{L} T_{c}}{\eta_{p}\left(T_{c}+\frac{\eta_{s}}{\eta_{1} \eta_{c} \eta_{d} \eta_{2}} T_{d}\right)} \\
\text { Equation (5): } \\
\text { Where } \quad P_{L}=\frac{P_{1}}{\eta_{3}}+\frac{P_{2}}{\eta_{4}}+\frac{P_{3}}{\eta_{5}}
\end{gathered}
$$

The equation (5) is debatable about the effect of each output of total amount of power.

The equation (5) gives the ability to charge lines in different ranges. The number of outputs is based on the number of supply voltages through DC-DC convertor in EPS convertor. For this Nano-satellite, three voltage levels are required for charging, including $3.3 \mathrm{v}, 5 \mathrm{v}$, and $12 \mathrm{v}$.

\section{The Elements Required Power}

The Nano-Satellite required power is depending on the required power of each element and their relation to each other for performance which is designable as a profile voltage. By considering the charge profile and the efficiency information, each of the EPS elements could be useful in electric power subsystem like solar

\begin{tabular}{|c|c|c|c|}
\hline Section name & $\begin{array}{c}\text { voltage } \\
\text { (V) }\end{array}$ & $\begin{array}{l}\text { current } \\
\text { (A) }\end{array}$ & $\begin{array}{l}\text { power } \\
(\mathrm{W})\end{array}$ \\
\hline \multirow{2}{*}{$\begin{array}{c}\text { Command controller } \\
\text { and } \\
\text { data management }\end{array}$} & \multirow[b]{2}{*}{3.3} & $336 * 10-6$ & $1.11 * 10-3$ \\
\hline & & $70 * 10-6$ & $2.31 * 10-4$ \\
\hline \multirow{2}{*}{$\begin{array}{l}\text { Subsystem controller } \\
\text { Situation control }\end{array}$} & \multirow{2}{*}{3.3} & $336 * 10-6$ & $1.11 * 10-3$ \\
\hline & & $70 * 10-6$ & $2.31 * 10-4$ \\
\hline \multirow{2}{*}{ Inertia measuring unit } & \multirow{2}{*}{5} & 0.07 & 0.35 \\
\hline & & $600 * 10-6$ & $3 * 10-3$ \\
\hline Star tracking & 5 & 0.4 & 2 \\
\hline GPS & 3.3 & $303 * 10-3$ & 1 \\
\hline \multirow[t]{2}{*}{ Solar sensor } & \multirow{2}{*}{5} & $5 * 10-3$ & $25 * 10-3$ \\
\hline & & $15 * 10-3$ & $75 * 10-3$ \\
\hline \multirow{2}{*}{ Reflective wheels } & \multirow{2}{*}{5} & 0.4 & 2 \\
\hline & & 0.02 & 0.1 \\
\hline \multirow[t]{2}{*}{ Subsystem controller } & \multirow[b]{2}{*}{3.3} & $336 * 10-6$ & $1.11 * 10-3$ \\
\hline & & $70 * 10-6$ & $2.31 * 10-4$ \\
\hline Thermal control subsystem & 12 & $209 * 10-3$ & 2.5 \\
\hline \multirow{3}{*}{ Sender and receiver } & \multirow{3}{*}{12} & $1 * 10-3$ & $12 * 10-3$ \\
\hline & & $95 * 10-3$ & 1.14 \\
\hline & & $545 * 10-3$ & 6.54 \\
\hline camera & 12 & $417 * 10-3$ & 5 \\
\hline G- frame & 5 & 0.8 & 4 \\
\hline
\end{tabular}
array and battery sizes. The required power of subsystems and elements, including voltage and current level must be keep updated throughout designing process for being accurate information for simulation in a repeatable process. This under study Nano-Satellite consists a set of standard satellite sub-systems presented in Table 1:

Table 1: Satellite Charges Specifications 


\section{The Charge Profile}

In order to modeling an electric power subsystem in this Nano-Satellite, different working modes should be considered. These modes have expanded based on aircraft commission by considering the required power of each mode. These modes are, including:

1) Usual Performance

2) Shot

3) Emergency Performance

The Figure 2 illustrates satellite charges power in an orbital period.

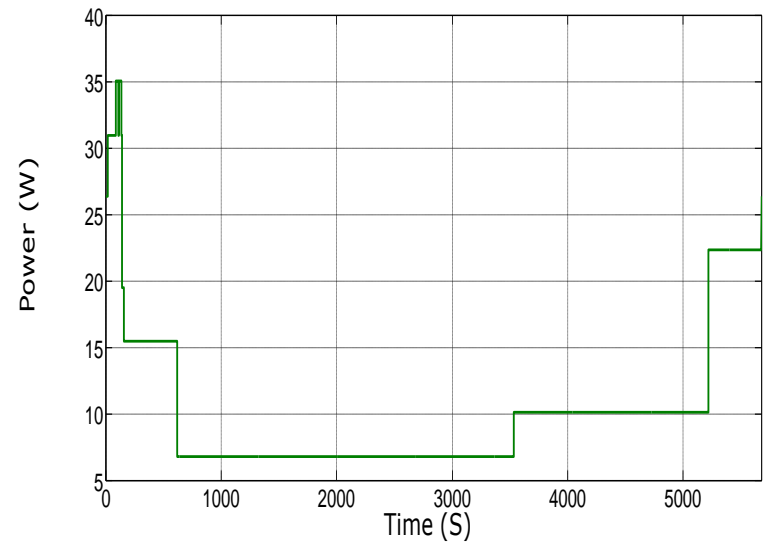

Figure 2: Charge Power Profile

\section{The Solar Arrays Design}

Previous surveys clear that the power gathered by satellites is depend on solar arrays sizes, photovoltaic panels' efficiency, and eclipse period length. These factors themselves are depend on other important factors, including solar intensity alteration, earth perihelion versus Aphelion, solar radiation angle, thermal considerations, and radiation effect in satellite longevity. There are two approaches for identifying solar arrays. In first approach we use the result of equation (5):

$$
\begin{aligned}
& P_{s a}=\frac{P_{L} T_{d}}{\eta_{p}\left(\eta_{s} \eta_{1} \eta_{c} \eta_{d} \eta_{2} T_{c}+\eta_{s} T_{d}\right)}+\frac{P_{L} T_{c}}{\eta_{p}\left(T_{c}+\frac{\eta_{s}}{\eta_{1} \eta_{c} \eta_{d} \eta_{2}} T_{d}\right)} \\
& \text { Where } P_{L}=\frac{P_{1}}{\eta_{3}}+\frac{P_{2}}{\eta_{4}}+\frac{P_{3}}{\eta_{5}}
\end{aligned}
$$

The power of this solar cell in surface unit obtains by equation (6):

$$
\text { Equation (7): } P_{0}=S . \eta_{\text {cell }}\left[\frac{\text { Watts }}{\text { Area }}\right]
$$

The equation (7) needs some corrections for fallowing reasons:

1) Solar radiation alteration during seasons

2) Solar cells efficiency reduction

Therefore $\mathrm{P}_{0}$ changes to $\mathrm{P}_{\mathrm{EOL}}$. So the required level of a cellular array expresses by equation (8) [2].

$$
\text { Equation (8): } A_{s a}=\frac{P_{s a}}{P_{E O L}} \quad[\text { Area] }
$$

According to equation (8), the power in surface unit taken from multiplication of sunlight intensity in each solar cell's efficiency. The approach is used to design the satellites that need freedom in terms of solar arrays size and direction. The second approach is used when there are some more effective elements for designing, including size, mass, volume, and transport and volume container. In this method, designing solar cells is possible through searching and maximizing efficiency of available surface for gathering solar power. The power profile limits to the maximum power. The under study Nano-Satellite project is a combination of both methods by a highlight on the second method. Although there are different structures for solar array structure, the structure in reference [5] will be considered due to selection the maximum solar arrays surface amount. 
Table 2: represents solar cells structures

\begin{tabular}{|l|c|}
\hline \multicolumn{1}{|c|}{ Solar CellName } & $\begin{array}{c}\text { Nominal } \\
\text { Efficiency }\end{array}$ \\
\hline 3 layer solar cell & $25.1 \%$ \\
\hline Improved 3 layer (ITJ) & $26.8 \%$ \\
\hline Extra 3 layer (UTJ) & $28.3 \%$ \\
\hline NeXt- 3 layer(XTJ) & $29.9 \%$ \\
\hline Advanced spatial 3 layer (ATJM) & $27 \%$ \\
\hline Advanced spatial 3 layer (ATJ) & $27.5 \%$ \\
\hline Spatial solar cell(BTJM) & $28 \%$ \\
\hline Spatial solar cell(BTJ) & $28.5 \%$ \\
\hline Spatial solar cell(ZTJM) & $29 \%$ \\
\hline (ZTJ)Spatial solar cell & $29.5 \%$ \\
\hline
\end{tabular}

The goal of this paper is to select the most suitable solar cells amount structure.

\section{The Power Distribution And Management}

Due to the problems of lack of electrical specifications consistency like charge, battery, and solar cells the use of a control system and power supply in solar arrays output and batteries is unavoidable. There are two several approach for designing satellite control system and power adjustment:

1. Direct Energy Transmission (DET)

In DET method the cell's solar energy transmits directly to the satellite changes without using of serial convertors and regulators.

2. Power Point Tracer system (PPT)

In PPT method the maximum power point tracer orbit is used instead of parallels regulators.

\section{The Battery}

Batteries are electrochemical cells that produce electrical current by chemical reactions. The batteries have the 5 bellow operational parameters:

1) Capacity

2) Energy

3) Life Limitation

4) Depth of Discharging

One of the crucial aspects of the satellite electrical power sub-system design is the number of battery charging and discharging cycles. In other words, the more discharging depth, the less number of durable battery cycles are. The more precise relation between these two variables is related to other parameters, although this is more related to battery chemical structure. Typically the producers report the number of complete discharging cycles which is $80 \%$ of the earlier capacity. For example if the battery rate is 300 cycles, this means that the producer guarantees that a battery capacity of 6.6 Ah retains a capacity of 5.28 Ah $(0.8 * 6.6=5.28)$ after 300 complete charging and discharging cycles. As far as the complete discharging cycles is not used in LEO orbit, the number of expected cycles for battery is adjustable according to Equation (9), (10), (11) and [7].

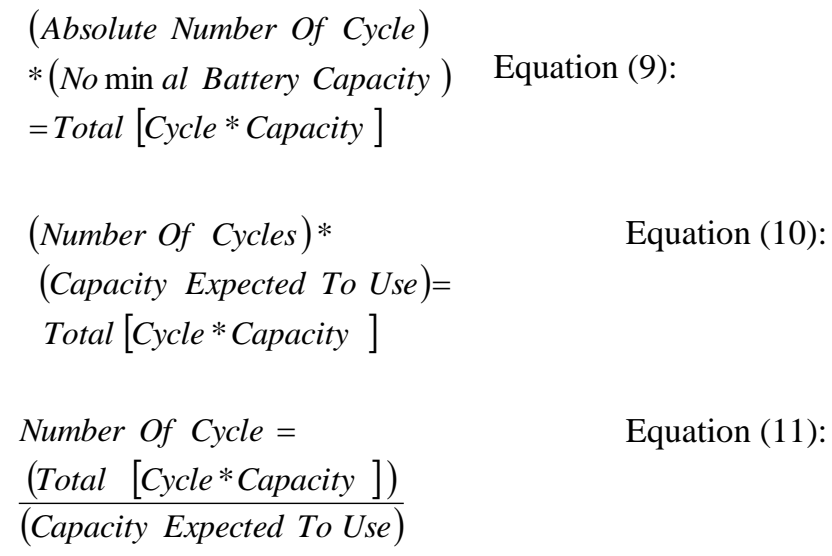




\section{Simulatıon}

The Figure 3 demonstrates the satellite electrical power system simulated in MATLAB software. We divide the satellite electrical power sub-system into 6 bellow sections:

1) Base circuit blocks

2) Sunlight intense and eclipse and non-eclipse time

3) Physical instant of solar cells, directing of solar cells, and cells array size

4) Scheduling and charges power

5) Power management and distribution subsystem, efficiency, and battery parameters

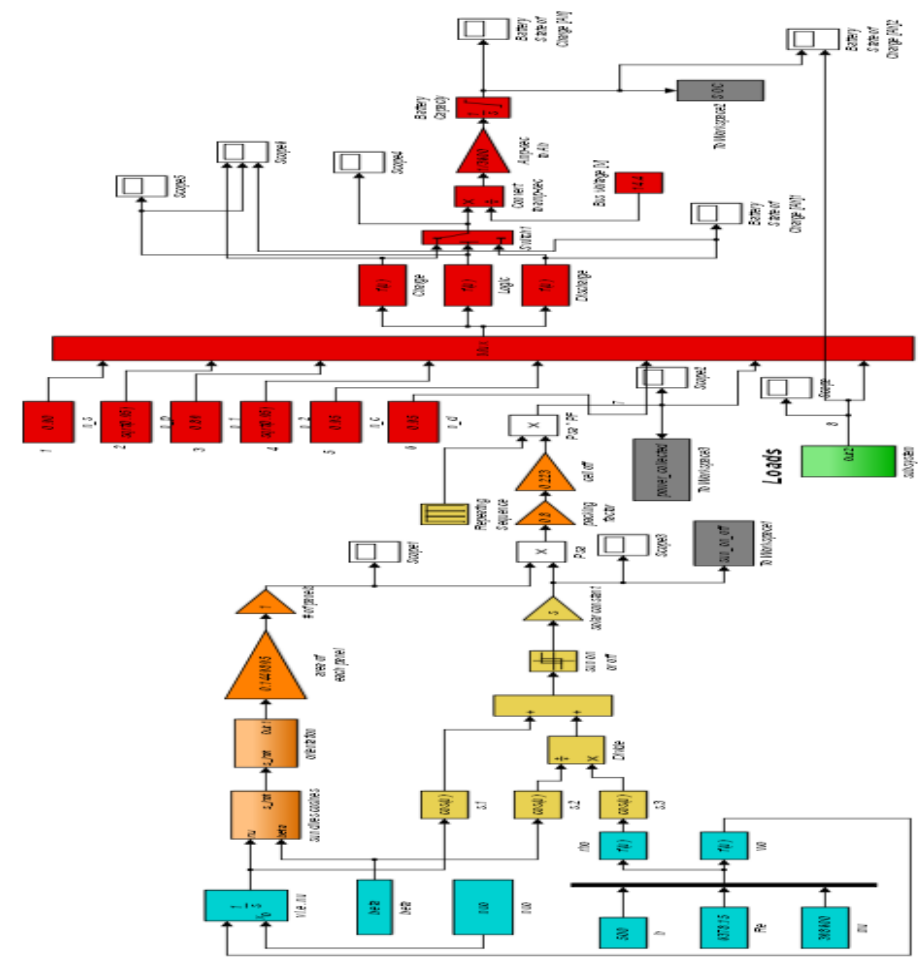

Figure 3): Satellite Electrical Power System

\section{8-1 Base Orbital Blocks}

The satellite alterative period obtains by equation (12):

$$
\text { Equation (12): } T=\frac{2 \pi}{\sqrt{\frac{\mu}{r^{3}}}}
$$

Which the satellite alterative period will be 94.6mins. The angular radius of earth, from the satellite point of view, is called rho, and defines in equation (13) [2]:

$$
\text { Equation (13): } \sin r h o=\frac{R_{E}}{R_{E}+h}
$$

The rho constant is used to define when satellite is in direct sunlight. This relation is represented conceptually in Figure 4.

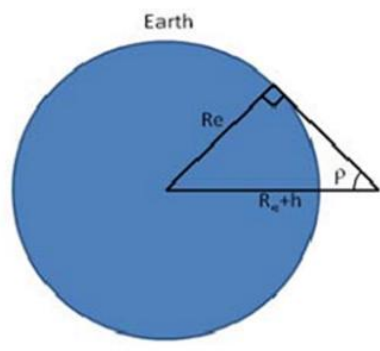

Figure 4: Geometrical relation between earth and satellite 


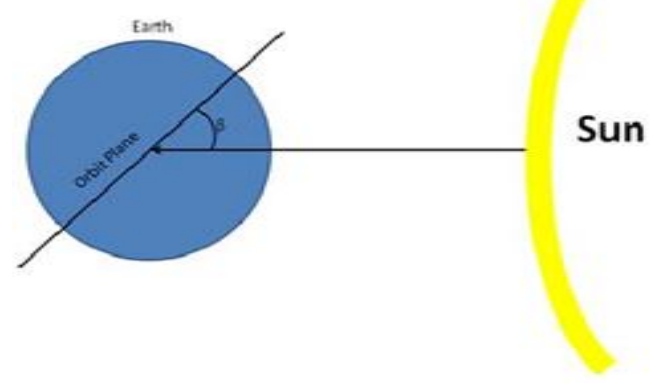

Figure (5): The angle between solar and panel

The Beta angle is an angle between solar radius and satellite circuit panel. This fact has shown in Figure 5. The Beta angle is used to predict the exact eclipse length in LEO pivot. There are two border amounts for Beta angle. Satellite never goes to eclipse when Beta angle is 90 grades. While the most lengthy eclipse time is when $\mathrm{Beta}=0$.

Duration of a satellite in eclipse is important from thermal and power production considerations. If Beta angle does not calculate during simulation, the real value should be selected for that. More, over as far as Beta value for earth position is similar to that of sun; a real value should be selected precisely for sun. These two values must be calculated in a real simulation time. However this leads to an unnecessary complexity. A suitable solution is to select the worst scenario based on combination of light intensity Beta angle and solar cells adjusted efficiency. The Figure 6 demonstrates Beta angle or a Nano-satellite, and sunlight above atmosphere with a sinusoidal function in 1414 to $1322 \mathrm{w} / \mathrm{m}^{2}$.

According to the least angle of Beta diagram by which the most lengthy eclipse duration occurs between March 21 and Jan 21. At this point the sunlight intensity is $1335 \mathrm{w} / \mathrm{m}^{2}$ and there is the most solar cells efficiency. Reversely, the minimum cells efficiency is close to the maximum point in December 21. At this time Beta is 3 grades. Simulation must be done in two both bellow case:

Case (1): light intensity of 1335 watt, Beta angle of 0 grades, solar cells efficiency of 0.223

Case (2): light intensity of 1414watt, Beta angle of 3 grades, solar cells efficiency of 0.203

In this simulation the inclination angle is considered 97.4 (Inclination=97.4)

It worth noticing that along with changing in inclination angle the Figure of Beta curve changes and a recalculation must be done.

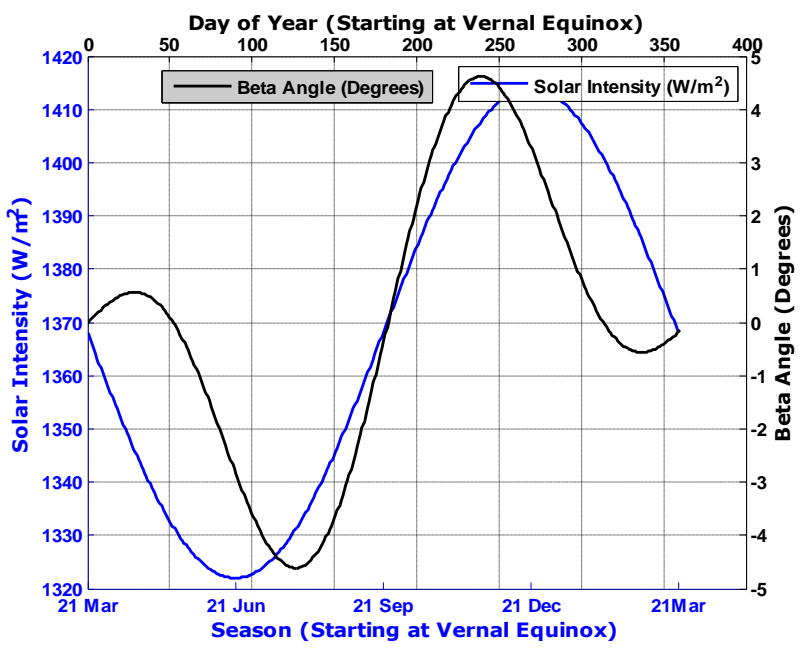

Figure 6: light intense and $\beta$ angle in terms of days of the year

8-2 Solar light intensity, and eclipse and non-eclipse times

If equation (14) [1] is true, then satellite is in eclipse.

$$
\text { Equation (14): } \cos v=-\frac{\cos \rho}{\cos \beta}
$$


Therefore, the satellite angle position updates through simulation, and equation (14) defines that whether satellite is in eclipse or not. From the physical point of view, the satellite is located in earth shadow. This leads to ON-OFF conditions and then products by solar constant values of 1335 or 1414.

\section{8-3 Solar Cells Physical Constants, Solar Cells Directing, And Cells Array Size}

In order to find the solar radiation angle on panels, the panels' situation compares with solar radiation side. The solar unit vector components on satellite are as equation (15) [1].

$$
\begin{aligned}
& s=-(\cos \beta \cos u) X_{0} \\
& \text { Equation }(15):-(\sin \beta) Y_{0} \\
&-(\cos \beta \cos v) Z_{0}
\end{aligned}
$$

Which $\mathrm{S}$ is solar unit vector, and $\mathrm{X}_{0}, \mathrm{Y} 0, \mathrm{Z} 0$ are vertical pivots on satellite body. These concepts are shown in Figure 7.

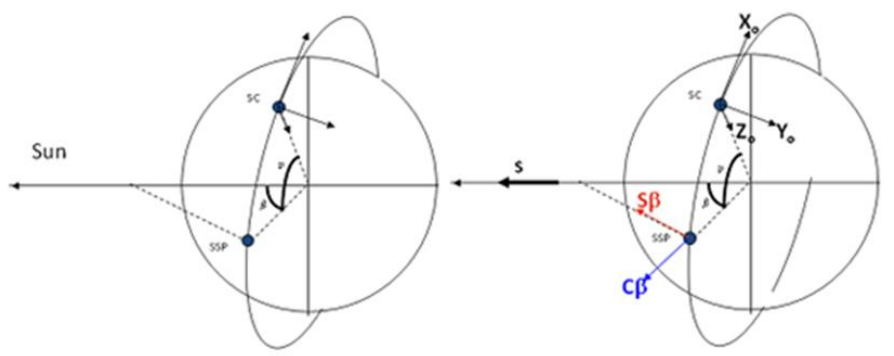

In this step the vector multiply point of previous equation and vertical vector on solar panels surface are calculating. As far as the satellite is on sun's side, except the first 620 seconds, the solar unit vector will have internal multiplication with itself which calculates in represented "Orientation" block.
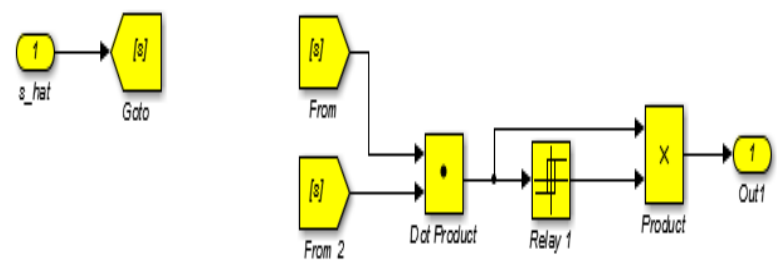

Figure 8: Orientation Block Content

\section{8-4 Scheduling and Charges Power}

The load subsystem block in Matlab software has shown in Figure (9).

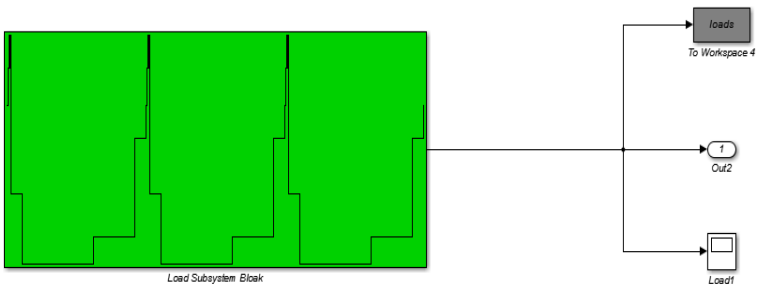

Figure 9: Available Charges of Electrical Subsystem

\section{8-5 Power management and distribution subsystem, efficiency, and battery parameters}

This section gets charges and power collected by solar arrays as input and determines that whether battery is charging and discharging. If the solar arrays power is more than total received power by charges, then the battery is charging. Instead, if the solar arrays power is less than total received power by charges, then the battery is discharging. This could be expressed mathematically as: 
Equation (16)

$$
\begin{array}{ll}
\text { Ch arge If } \left.\quad \eta_{s} P_{s a}\right\rangle & P_{L} / \eta_{P} \\
\text { Disch arge If } & \eta_{s} P_{s a}\left\langle P_{L} / \eta_{P}\right.
\end{array}
$$

In charging time the produced power by solar arrays divides between charges and battery. See equation (17):

$$
\text { Equation (17): } P_{s a}=\frac{P_{L}}{\eta_{p} \eta_{s}}+\frac{P_{b c}}{\eta_{c} \eta_{1} \eta_{s}}
$$

As it is clear, the DC-DC convertor and line loss will not be considered because there are not located in "charge" green blocks set and do not consist of PMAD control blocks. After solving the above equation, the power in battery charging state calculates as equation (18):

$$
\text { Equation (18): } P_{b c}=\left(P_{s a} \eta_{s}-\frac{P_{L}}{\eta_{p}}\right) \eta_{1} \eta_{c}
$$

In discharging states, the produced power by solar cells is not sufficient for charges required power supply. At this state any power cannot transmit from solar cells to battery. The required charges power is like equation (18):

$$
\text { Equation (19): } P_{L}=P_{S a} \eta_{s} \eta_{p}+P_{b d} \eta_{d} \eta_{2} \eta_{p}
$$

The equation (19) demonstrates that the battery is charging or discharging.

$$
\text { Equation (20): } P_{S a} \eta_{s}-\left(\frac{P_{L}}{\eta_{P}}\right)
$$

\section{8-6 simulation results}

The Figures 10 and 11 present the simulation results with earlier conditions of case (1) and (2). The part A of Figures 10 and 11 are related to collected power. The blue lines depict whether satellite is in eclipse or not; green lines show the total amount of power by satellite. In cases (1) and (2), 35 and 34 watt of power have collected, respectively. Due to the "Power Factor "block the difference equals to zero. Physically, the satellite is in imaging state, so it does not collect any power. In the first 620seconds batteries do not charge, and the required power for imaging supplies in discharging through batteries. The part B of Figures 10 and 11 demonstrates charge profile and battery charging state; load profile and discharging state by blue and green lines, respectively.For instance locations where charge power have great leap, the negative slope of SOC lines is greater. One of the most important aspects of SOC lines is that whether the maximum battery level is $5.2 \mathrm{Ah}$ at the end of orbit on panels is accessible or not.

In this case the SOC lines reach to their $100 \%$ charge and satisfy the orbital energy balance. As it is shown in results, the early charge level is 502Ah which reduces to $4.45 \mathrm{Ah}$. Therefore the battery retains $85.5 \%$ charge which leads to $14.5 \%$ of DOD. According to this discharging depth we can use batteries that could endure approximately 3000 charging and discharging cycles.

\section{Conclusion}

As it is shown in simulations the result of cases 1 and 2 are similar. This was not easy to discriminate without simulation. According to simulation results and battery discharging depth, it is recommended to select cells by efficiency of $27 \%$-namely ATJM solar cell for satellite which leads satellite weight, dimension and size reduction and also satellite better efficiency.

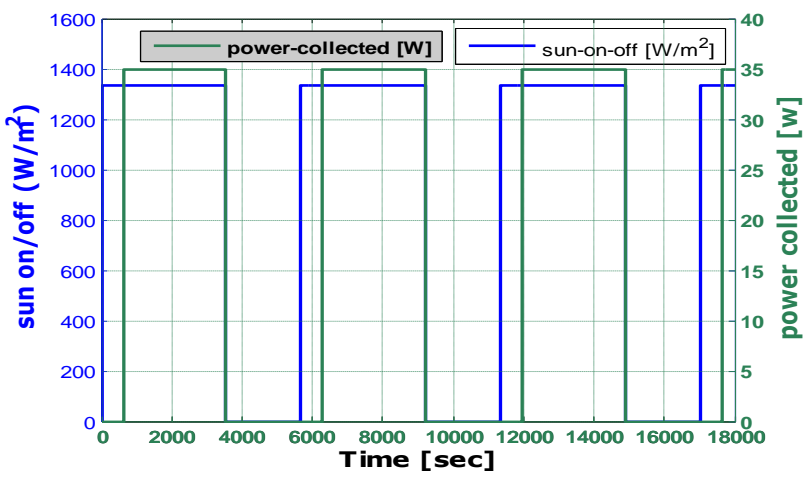




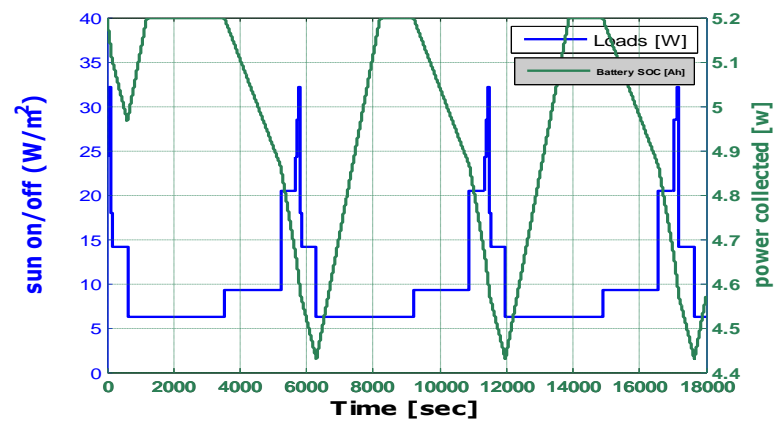

Figure 10: Output of case (1)
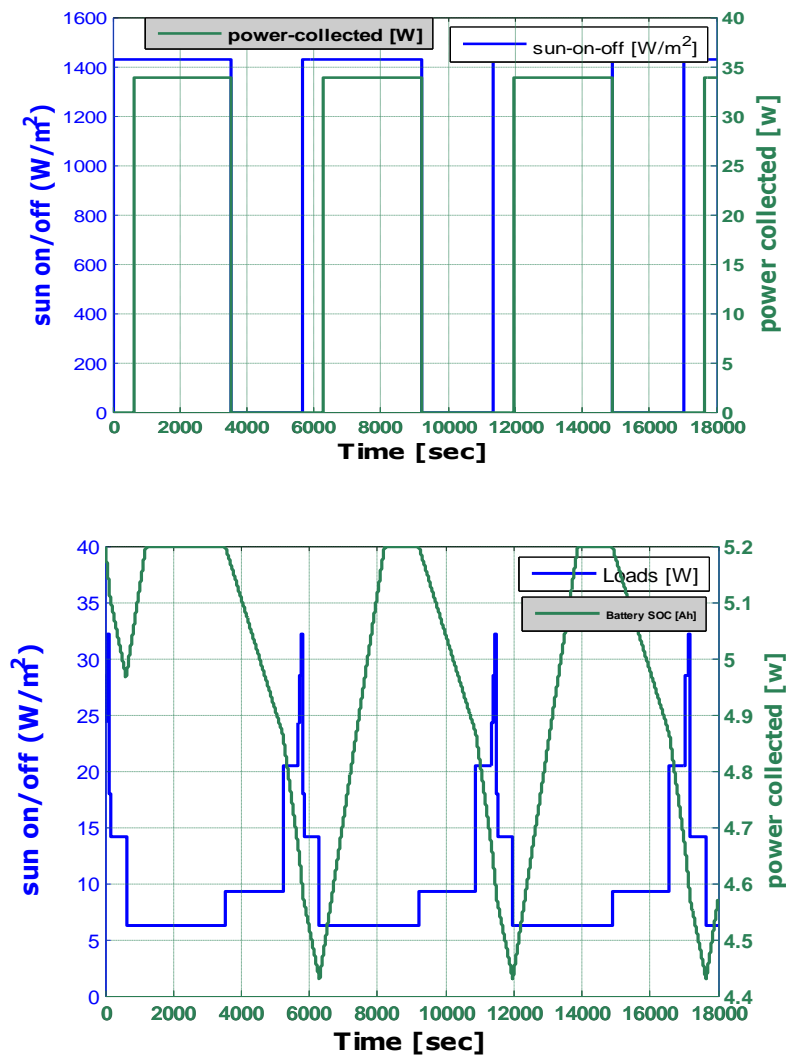

Figure 11: Output of case (2)

\section{Reference}

[1]. Jamila E., and Abdelmjid S., "Physical Modeling of A Hybrid Wind Turbine-Solar Panel System Using Simscape Language", IJE Transactions B: Applications Vol. 27, No. 11 (November 2014) 1767-1776.

[2]. Toloei A., Abbaszadehtoori M., Shayan M., 'Attitude Estimation of Nano-Satellite According To Navigation Sensors Using of Combination Method', IJE Transactions A: Basics Vol. 28, No. 7 (July 2015) 964-969.

[3]. H. Gholizade-Narm, "A Novel Control Strategy For A Single-Phase Grid-Connected Power Injection System”, IJE Transactions C: Aspects Vol. 27, No. 12 (December 2014) 1841-1849.

[4]. DenHerder T., "Desigenandsimulationofphotovoltaic super system usingsimulink", CaliforniaPolytechnic State University, (2013).

[5]. Oi A., "Desigen And Simulation of photovoltaic water pumping system", Thesis Presented to the Faculty of California Polytechnic State University, September (2010).

[6]. $\quad$ Erickson R. W., Makimovic D., "Introduction topower electronics", Springer (2009).

[7]. Leonard B., "AE3804 Thermal Control of Spacecraft Class Notes", (2013).

[8]. Masoum M. A. S., Sarvi M ., " Design, simulation and Construction of a new Maximum power point tracker for photovoltaic applications", Springer (2012).

[9]. Ahmadzadehtalatapeh M., "Erformance Study of A Solar Integrated Central Heating System of A Residential Building Using Trnsys- An Hourly Simulation Model”, IJE Transactions C: Aspects Vol. 27, No. 3 (March 2014) 457-466. 